\section{Primate Puzzles}

Female Choices. Sexual Behavior of Female Primates

By Meredith F. Small (1993). Ithaca; Cornell University Press. xi +245 pp. $\$ 26.95$ (cloth). ISBN 0-8014-2654-5.

Faces in the Forest: The Endangered Muriqui Monkeys of Brazil

By Karen B. Strier (1992). New York: Oxford University Press. xix $+138 \mathrm{pp}$. $\$ 45.00$ (cloth). ISBN 0-19-506339-2.

The behavior of females and the behavior of platyrrhines are among the most fashionable topics in contemporary primatology, and justifiably so. Two recent books epitomize the interest in these subjects. Meredith Small's lively review summarizes the available data on the sexual behavior of female primates including humans and argues that females are not as "choosy" as predicted by traditional sexual selection theory. ${ }^{1}$ Karen Strier's semipopular account of a decade of research on the behavioral ecology of the muriqui, Brachyteles arachnoides, portrays a species that confounds the expectations of the influential "female-bonded" model of the relationship between primate diet and social organization. ${ }^{2}$ Strier's study of a species that is a specific case of Small's general thesis links these two books. Female muriquis copulate with multiple males, sometimes in quick succession.

Strier set out to test Wrangham's model $^{2}$ of the adaptive significance of primate social groups characterized by female philopatry (lifelong residence in the natal group) as well as by elaborate, differentiated female-female cooperative and competitive relationships. These social groups, found most often among cercopithecoids, were hypothesized to function cooperatively primarily to defend food resources against other groups. They were predicted to exist within species that, when possible, exploit concentrated, high-quality food patches (usually fruiting trees) but, when necessary, are able to fall back, sometimes seasonally, on more evenly distributed, low-quality food (vegetative plant parts). This spatio-temporal distribution allows females to stay together during lean periods and provides them with resources that repay the costs of cooperative defense in times of plenty. In contrast, within species such as chimpanzees and spider monkeys, which rely on ripe fruit, semi-solitary females disperse, whereas philopatric males cooperate to defend their access to females against rival groups of males. In species such as mountain gorillas, which subsist on low-quality food, female gregariousness has functions other than resource defense (e.g., maintenance of proximity to an adult male that can protect against infanticide). These females may transfer between groups. Moreover, female-female social bonds are weak.

Before presenting her data and conclusions, Strier offers an engaging personal account of the challenges and triumphs of setting up a primate field site. Ten years of study have established muriquis as one of a growing set of departures from the female-bonded model. ${ }^{3}$ When it is available, they feed on fruit, preferably in large concentrations, and when fruit is scarce, they eat leaves. But males are philopatric, whereas almost all females transfer. Adults of both sexes participate in aggressive intergroup vocal displays. Strier argues that: female transfer is primitive for the anthropoids; ${ }^{4}$ sexual monomorphism in Brachyteles has selected for kin-based cooperative male defense of "independent females who cannot be bullied" (p. 89) and for male deference to females in feeding and mating contexts; female transfer is an inbreeding avoidance mechanism; and large body size (15 kg) and consequent high risks of arboreal fighting have selected for the phenomenally low muriqui intragroup aggression rate. No dominance hierarchies are discernible. Sperm competition has replaced intermale aggression within social groups. Brachyteles fits nicely into the well-established cross-species correlation between breeding system and relative testes size: that is, when females commonly copulate with multiple males during a single estrous period, testes are larger than in single-male (monogamous or harem) breeding systems. ${ }^{5}$

Recent modeling and supporting comparative data indicate that food abundance and distribution may separately and respectively affect interand intragroup female-female competition. ${ }^{6}$ Whenever food availability limits female reproduction, groups will aggressively compete and group size will be positively correlated with home-range size. Certainly the first of these conditions characterizes Brachyteles, ${ }^{7}$ the second tentatively does so. Clumped, as opposed to dispersed, food resources will generate intragroup feeding competition, reflected in strong female dominance hierarchies and a positive correlation between group size and day-range length. Muriquis definitely lack the former, but may have the latter. ${ }^{7}$ Thus, more data on several social groups are needed to determine whether Brachyteles fits this model. In any case, the rare combination of female transfer and female participation in intergroup aggression is striking from the standpoint of all existing models of primate social organization. ${ }^{8}$

Only about 500 muriquis remain in the wild, and these are scattered among a dozen forest fragments. Strier devotes a chapter to the conservation controversies, such as the costs versus the benefits of translocation, that straddle the boundary between science and politics. Field primatologists can no longer evade the practical and ethical demand to serve as advocates for, not just observers of, their study animals. The history of the campaign to protect the muriqui illustrates how difficult and how rewarding this work can be.

Besides challenging the femalebonded model, the muriqui also departs from traditional views of gender differences in mating strategies, and therefore forms one thread in the colorful tapestry that Small weaves. In breezy, nontechnical language, she addresses a series of historical and contemporary controversies. These range from the importance of female mate choice as seen by the originators of the theory of natural selection (Darwin thought it had little impact on evolution, Wallace thought it had none) to 


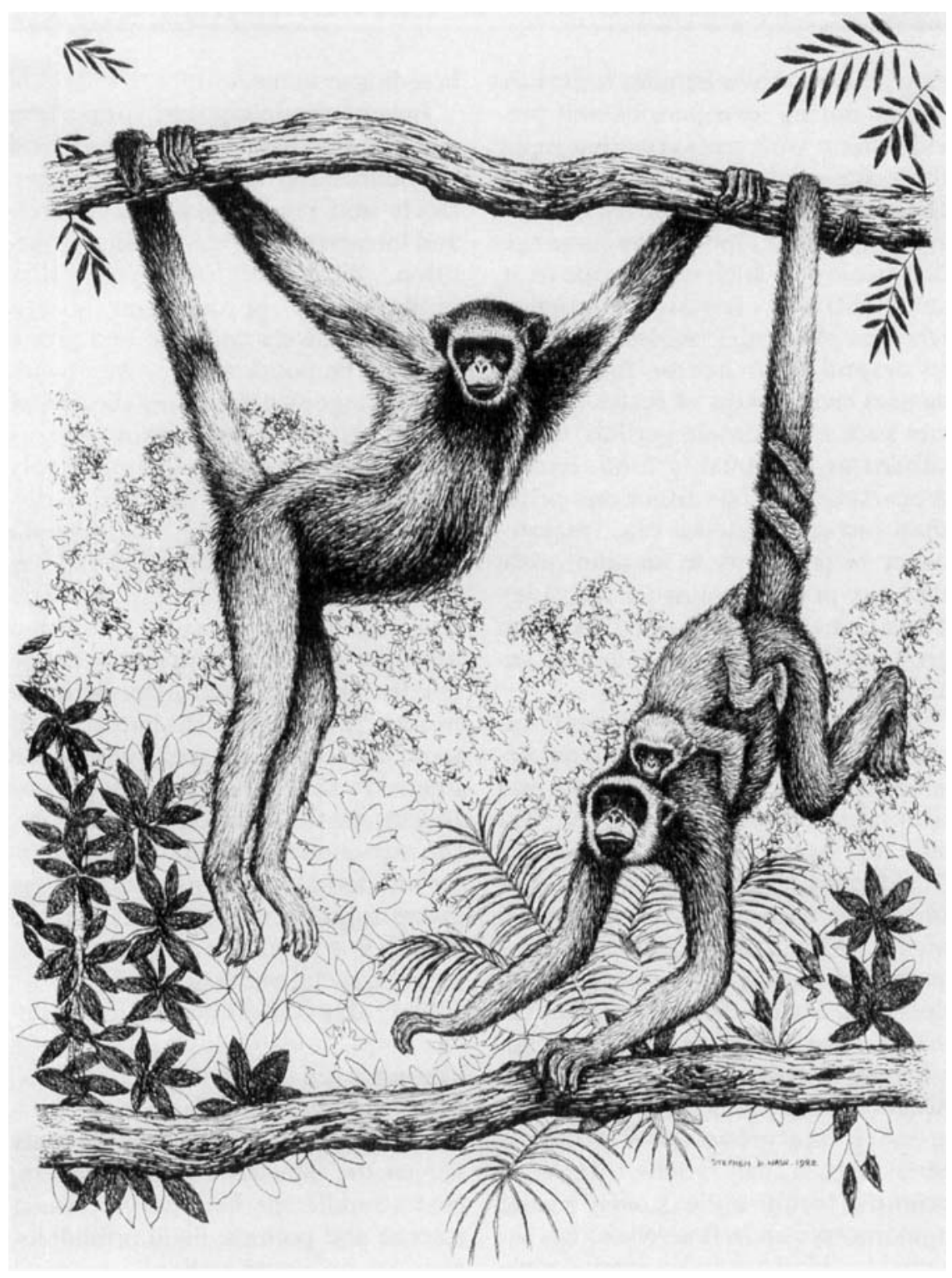

The muriqui, Brachyteles arachnoides, from southeastern Brazil. Drawing by Stephen Nash.

the adaptive significance of female orgasm. Here I shall focus on three issues: the utility of "female mate choice" as an organizing concept for understanding female primate behavior; explanations for apparently nonselective mating by females; and our current understanding of human female strategies.

Mate choice can be defined as behavior by members of one sex that alters the probability of mating with particular members of the opposite sex. ${ }^{9}$ Gender differences in minimal parental investment lead us to expect females to exercise greater mate selectivity than males do.' A large body of data from many animal taxa supports
In Small's view, the blinders produced by this theoretical edifice cause primatologists to confuse female mate choice with generalized female sexual assertiveness. Females of some species appear to seek copulations per se rather than with particular males. However, we must distinguish between female motivation and the effects on differential male mating success of female behavior, or proximate from ultimate levels of explanation. Small does not do this consistently. Regarding proximate explanation, I suspect that, among primates living in multi-male social groups, evolved species-specific rules governing female mating behavior embody elements of both choice and "promiscuity"-e.g., "copulate with all males, besides your matrilineal relatives, that rank above threshold level $x$ in attribute $a$ ".13 Moreover, these rules of decision incorporate environmental input, permitting adaptive flexibility. Thus, females' criteria for mate choice will vary within species depending on group characteristics such as demographic conditions and even individual characteristics such as female age and dominance rank.

This theoretical framework, though somewhat unwieldy, is more productive than arguments about the general nature ("choosy" or "promiscuous") of female primates. For instance, despite Small's unsubstantiated dismissal of this finding, when male troop membership is stable female savanna baboons favor as mates males that have invested in them and their offspring in the past. ${ }^{14}$ But when male troop membership is unstable, females choose new immigrants that are likely to remain in the group long enough to care for the infants they probably have fathered. ${ }^{15}$ Small keenly points out ideological undertones in portrayals of choosy females, but we should not throw out the baby (female mate choice) with the bathwater (the vestigial Victorian belief in passive females).

What about those cases-muriquis for example, and Barbary macaquesin which females, aided by males' tolerance of one another's mating activity, really do appear undiscriminating? Small rejects the nonadaptive hypothesis that selection 
for male promiscuity has unavoidably produced, to a lesser degree, female promiscuity, ${ }^{16}$ as well as various versions of the paternity confusion hypothesis (e.g., infanticide prevention ${ }^{17}$ ) in favor of two other hypotheses:

The sperm scarcity hypothesis, that females seek sperm from multiple males to ensure conception, was first published in $1988^{18}$ but has not yet been seriously tested. Small argues that demonstrated negative correlations between the ratio of adult females to males and birth rate show the limiting effects of sperm supply on female reproductive success. But these findings in baboons ${ }^{19}$ are subject to alternative interpretations, such as female-female reproductive suppression. ${ }^{20}$ Similar findings in harem-living hanuman langurs are irrelevant to female promiscuity in multi-male group-living species. ${ }^{21}$ The relationship between fertility and adult sex ratio should and could be explored in the several colonies of semi-free-ranging Barbary macaques. Experiments with captive nonhuman primates could determine whether conception is more likely when fertile females are allowed sequential access to multiple males than when they are inseminated by a single male. A promising alternative to the sperm scarcity hypothesis is that females actively promote sperm competition. ${ }^{22,23}$ Consider a species in which females, for whatever reason, occasionally mate with multiple males. For example, females in synchronously breeding species may accept less preferred partners while waiting for more highly preferred partners to become available. Selection on males will then favor production of more and better sperm. This, in turn, will exert Fisherian selection on females to seek fertilization by males that produce high quality ejaculates. ${ }^{24}$ Females can accomplish this by commonly mating with multiple males and maintaining physical and chemical features in their reproductive tracts $^{24}$ that are sufficiently hostile to "test" sperm, yet not so hostile as to reduce fecundity. These traits and behaviors will create even more sperm competition, in runaway fashion. The prevalence of female anti-sperm responses casts doubt on the generality of the sperm scarcity hypothesis. If conception were as problematic as Small proposes, selection would make the female reproductive tract friendlier to sperm, rather than producing the risky behaviors necessary, in most species, to copulate with multiple males. Unlike the sperm scarcity hypothesis, the sperm competition hypothesis predicts postcopulatory female mate choice - a topic that Small briefly reviews, but neglects to integrate into her interpretations. I expect that the general issue of postcopulatory female mate choice in primates will receive considerable attention in the next few years. Such choices can be as simple as selective physical removal of mating plugs by females (as happens in muriquis) or as complex as selective immune responses to sperm.

The second hypothesis favored by Small is that females that conceive each offspring with a different male will have higher long-term reproductive success. This hypothesis is supported by data showing that female Japanese $^{25}$ (and possibly rhesus ${ }^{26}$ ) macaques develop sexual aversion to males that have been in their social group for more than two years. Data on the proposed fitness benefits will be extremely difficult to obtain. The theoretical basis for this hypothesis is underdeveloped. Models have shown that conditions such as sibling competition in unpredictable environments favor varied paternity. However, it has not been demonstrated that those conditions are important in primates. ${ }^{22}$ Indeed, other data support the opposite hypothesis, that females will seek the same male or closely related males to father their offspring, which will then be closely related and likely to cooperate in intergroup competition. ${ }^{27}$

How can the study of nonhuman primate females provide insights into the evolution of human female behavior? In her final chapter, Small uses various explanatory frameworks. One of these is phylogenetic inertia: "Because we share with nonhuman primate females many of our broad patterns of behavior, we may also share our sexual nature" (p. 187). She also discusses clashes between "natural" and "cultural" influences on behavior: "No matter what our culture tells us...the basic core remains the same" (p. 217). In some contexts she takes an adaptationist perspective: "It may be that a woman is executing an evolutionary strategy when she commits adultery" (p. 217). Because of the absence of an explicit rationale for deciding when to use each type of explanation, this chapter is somewhat unfocused. Small devotes considerable space to demolishing the argument, seldom heard in recent years, that humans are "naturally preprogrammed monogamous beings." As an alternative, she implies that humans are "naturally" promiscuous, but that marriage is imposed on us by "society." Disappointingly, Small does not attempt to describe the game-theoretical models than can generate hypotheses about the evolution of mixed reproductive strategies in both sexes. ${ }^{28}$ In some passages, she equates society as a causal agent with male sexual coercion of women..$^{29}$ Small rightly points out that the threat of male aggression constrains female sexual behavior and, even in our own society, limits our ability to collect accurate information about female preferences. A long history of hominid male sexual coercion is suggested by its high cross-cultural frequency, its taxonomically widespread occurrence in nonhuman primates ${ }^{30}$ and, most convincingly, the theoretically derived prediction that parentally investing males (the norm in Homo sapiens) will take drastic measures to increase paternity confidence. ${ }^{31}$ Because social, material, and genetic benefits can sometimes accrue to females via extra-pair copulations, selection probably has favored hominid females' ability to circumvent coercion by established mates. To the potpourri of scenario-building elements, I add the speculation that selective pressure on both females and males to arrange clandestine copulations along with counter-pressure to detect them and communicate about them, were powerful forms of selection for "social intelligence," widely held to be responsible for hominid brain expansion. ${ }^{32}$

Female mate choice and related issues will command increasing attention from primatologists and human behavioral ecologists. Several promising research techniques are available. 
DNA fingerprinting, ${ }^{33}$ among other advances, will permit indirect measurement of sperm competition and postcopulatory female mate choice through the examination of discrepancies between paternity and male copulatory frequency during peak female fertility.

Investigation of morphological, and especially facial symmetry as a mate choice criterion may be useful. Although most primates lack the elaborate ornaments that, in other taxa, may signal "good genes," symmetry may be honest advertising of superior resistance to developmental stress. ${ }^{34}$ Other approaches include experimental manipulation of partner choice options and contexts in captive nonhuman primates, ${ }^{35}$ phylogenetic analysis of the evolution of primate mating systems, ${ }^{36}$ and both inter- and intracultural comparisons of the costs and benefits of different mating strategies in humans. ${ }^{27}$

In different but complimentary ways, these books sample the evolving primatological "meme pool." Female Choices, with its accessible literature reviews, provocative arguments, and entertaining style, is a worthwhile purchase at $\$ 26.95$. Faces in the Forest, a highly readable account of a behaviorally atypical primate barely rescued from extinction, is essential reading for anyone interested in primate socioecology or conservation.

\section{REFERENCES}

1 Trivers RL (1972) Parental investment and sexual selection. In Campbell B (ed), Sexual Selection and the Descent of Man 1871-1971, pp 136-179. Chicago: Aldine.

2 Wrangham RW (1980) An ecological model of female-bonded primate groups. Behaviour 75:262-300.

3 Stanford CB (1991) The Capped Langurs of Bangladesh: Behavioral Ecology and Reproductive Tactics. Basel: Karger.

4 Strier KB (1990) New World primates, new frontiers: Insights from the woolly spider monkey, or muriqui (Brachyteles arachnoides). Int J Primatol 11:7-19.

5 Harvey PH, Harcourt AH (1984) Sperm competition, testes size, and breeding systems in primates. In Smith RL (ed). Sperm competition and the Evolution of Animal Mating Systems, pp 589-600. New York: Academic Press.

6 Isbell LA (1991) Contest and scramble competition: Patterns of female aggression and ranging behavior among primates. Behav Ecol 2:143-155. 7 Strier KB (1987) Ranging behavior of woolly spider monkeys, or muriquis, Brachyteles arachnoides. Int J Primatol 8:575-591.

8 Manson JH, Wrangham RW (1991) Intergroup aggression in chimpanzees and humans. Curr Anthropol 32:369-390.
9 Halliday TR (1983) The study of mate choice. In Bateson P (ed) Mate Choice, pp 3-22. Cambridge: Cambridge University Press.

10 Harvey PH, Bradbury JW (1991) Sexual selection. In Krebs JR Davies NB (eds), Behav ioural Ecology: An Evolutionary Approach, pp 203-233. Oxford: Blackwell.

11 Balmford A, Read AF (1991) Testing alternative models of sexual selection through female choice. Trends Ecol Evol 6:274-276.

12 Fisher RA (1915) The evolution of sexual preference. Eugen Rev 7:184-192.

13 Manson JH (1992) Measuring female mate choice in Cayo Santiago rhesus macaques. Anim Behav 44:405-416.

14 Smuts BB (1985) Sex and Friendship in Ba boons. New York: Aldine.

15 Bercovitch FB (1991) Mate selection, consortship formation, and reproductive tactics in adult female savanna baboons. Primates 32:437 452 .

16 Halliday T, Arnold SJ (1987) Multiple mat ings by females: A perspective from quantitative genetics. Anim Behav 35:939-941.

17 Hrdy SB (1981) The Woman That Never Evolved. Cambridge: Harvard University Press.

18 Small MF (1988) Female primate sexual behavior and conception: Are there really sperm to spare? Curr Anthropol 20:81-100.

19 Dunbar RIM, Sharman M (1983) Female competition for access to males affects birth rate in baboons. Behav Ecol Sociobiol 13:157-159.

20 Wasser SK, Barash DP (1983) Reproductive suppression among female mammals: Implications for biomedicine and sexual selection theory. Quart Rev Biol 58:513-538.

21 Sommer V, Srivastava A, Borries C (1992) Cy cles, sexuality, and conception in free-ranging langurs (Presbytis entellus). Am J Primatol 28:1-27.

22 Knowlton N, Greenwell SR (1984) Male sperm competition avoidance mechanisms: The influence of female interests. In Smith RL (ed), Sperm Competition and the Evolution of Animal Mating Systems, pp 61-84. New York: Academic Press.

23 Bellis MA, Baker RR (1990) Do females promote sperm competition? Data for humans. Anim Behav 40:997-999.

24 Birkhead TR, Møller AP, Sutherland WJ (1993) Why do females make it so difficult for males to fertilize their eggs? J Theor Biol 161:51-60.

25 Huffman MA (1991) Mate selection and partncr preferences in female Japanese macaques. In Fedigan LM, Asquith PJ (eds), The Monkeys of

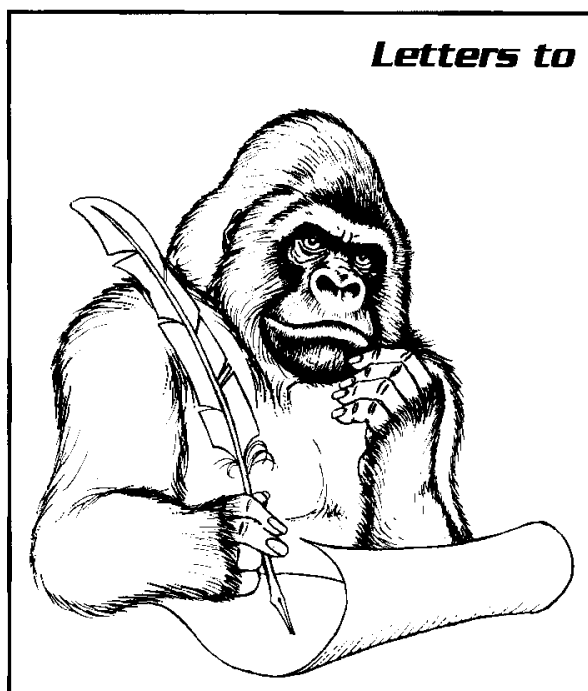

Arashiyama: Thirty-five Years of Research in Japan and the West, pp 101-121. New York: SUNY Press.

26 Chapais B (1983) Structure of the birth season relationship among adult male and female rhesus monkeys. In Hinde R (ed), Primate Social Relationships: An Integrated Approach, pp 200 208. Oxford: Blackwell.

27 Silk JB, Boyd R (1983) Cooperation, competition, and mate choice in matrilineal macaque groups. In Wasser SK (ed), Social Behavior of Female Vertebrates, pp 315-347. New York: Academic Press.

28 Borgerhoff Mulder M (1992) Reproductive decisions. In Smith EA, Winterhalder B (eds), Evolutionary Ecology and Human Behavior, pp 330-374. New York: Aldine.

29 Smuts BB (1992) Male aggression against women: An evolutionary perspective. Hum $\mathrm{Na}$ ture 3:1-44.

30 Smuts BB, Smuts RW (1992) Male aggression and sexual coercion of females in nonhuman primates and other mammals: Evidence and theoretical implications. In Slater PJB, Rosenblatt JS, Milinski M, Snowdon CT (eds), $A d$ vances in the Study of Behavior, Vol. 22, pp 1-63. New York: Academic Press.

31 Daly M, Wilson M, Weghorst SJ (1982) Male sexual jealousy. Ethol Sociobiol 3:11-27.

32 Humphrey NK (1976) The social function of intellect. In Bateson PPG, Hinde R (ed), Growing Points in Ethology, pp 303-317. Cambridge Cambridge University Press.

33 Martin RD, Dixson AF, Wickings EJ (eds) (1992) Paternity in Primates: Genetic Tests and Theories. Basel: Karger.

34 Møller AP (1990) Fluctuating asymmetry in male ornaments may reliably reveal male quality Anim Behav 40:1185-1187.

35 Keddy AC, Seyfarth RM, Raleigh MJ (1989) Male parental care, female choice, and the effect of an audience in vervet monkeys. Anim Behav 38:262-271.

36 Harvey PH, Pagel MD (1991) The Comparative Method in Evolutionary Biology. Oxford: Oxford University Press.

\section{Joseph H. Manson Department of Anthropology The University of Michigan Ann Arbor, MI \\ (ㄷ) 1993 Wiley-Liss, Inc}

